\title{
LIBERDADE RELIGIOSA: UMA QUESTÃO DE TOLERÂNCIA OU RESPEITO?*
}

\author{
RELIGIOUS LIBERTY: A MATTER OF TOLERANCE OR RESPECT?
}

\section{Maria Costa Neves Machado**}

\begin{abstract}
Resumo:
Neste artigo são examinadas duas possiveis abordagens filosóficas que ordenamentos jurídicos de democracias liberais podem adotar quando se trata de solucionar problemas jurídicos envolvendo questões religiosas: a tolerância ou o respeito. Assim, na primeira parte é realizada uma análise crítica sobre a diferença entre o princípio da tolerância e o do respeito no que se refere ao tratamento legal de questões de consciência. A seguir, a regulamentação da liberdade religiosa no ordenamento jurídico brasileiro é examinada com a finalidade de verificar qual desses dois princípios é adotado. Finalmente, conclui-se que o ordenamento jurídico brasileiro adota o princípio do respeito pela faculdade dos indivíduos de buscarem a finalidade última da vida, sendo o Estado obrigado a fornecer condições adequadas para as pessoas exercerem tai faculdade autonomamente, de modo que todos os indivíduos entrem no espaço público em condições iguais.
\end{abstract}

Palavras-Chave: Liberdade religiosa. Liberdade de culto. Tolerância. Respeito. Acomodação.

\begin{abstract}
:
This paper analyzes two different philosophical approaches that legal systems of liberal democracies can adopt in order to address problems related to religious matters: tolerance and respect. Thus, in the first part of this paper, the conceptual difference between the tolerance principle and the respect principle concerning legal issues involving conscience matters is examined. Then, the rules concerning religious liberty in the Brazilian legal system are analyzed for the purpose of verifying which of these two principles is adopted. Finally, this article concludes that the Brazilian legal system adopts the principle of respect for the faculty to search for the ultimate end of life and that the State has the duty to provide adequate conditions for individuals to autonomously exercise such faculty, so that all citizens can participate in the public sphere on equal conditions.
\end{abstract}

Keywords: Religious liberty. Freedom of worship. Toleration; Respect. Accommodation.

Este artigo, com pequenas modificações, foi apresentado em junho de 2009 para conclusão de The law and philosophy workshop: toleration and religious liberty (set./2008-mai./2009), coordenado por Martha Nussbaum e Brian Leiter, na University of Chicago Law School.

. Advogada, mestra em Direitos Humanos pela Universidade de São Paulo (2008) e mestra em Direito (LL.M.) pela University of Chicago Law School (2009). Email: mariacnmachado@usp.br. 


\title{
1. Introdução
}

Há duas possíveis abordagens que sistemas jurídicos de democracias liberais podem adotar quando se trata de solucionar problemas jurídicos envolvendo questões religiosas: a tolerância ou o respeito. Enquanto alguns autores argumentam que para lidar com questões religiosas se deve aplicar o princípio da tolerância, ${ }^{1}$ outros sustentam que este não é suficiente para garantir a dignidade humana e que se faz necessário respeitar as crenças e práticas religiosas dos indivíduos. ${ }^{2}$

Inicialmente, para examinar essa questão, a diferença entre o princípio da tolerância e o do respeito é criticamente analisada (item 2). Posteriormente, o ordenamento jurídico brasileiro é estudado com a finalidade de verificar se as leis brasileiras estão de acordo com o princípio do respeito ou da tolerância quando se trata de questões envolvendo liberdade religiosa (item 3). Finalmente, conclui-se que o ordenamento jurídico brasileiro adota o princípio do respeito pela faculdade dos indivíduos de buscarem a finalidade última da vida (item 4).

\section{Tolerância ou respeito?}

Para comparar os dois princípios que podem orientar a solução de conflitos jurídicos envolvendo questões religiosas em democracias liberais, é importante definir, de um lado, o conceito de tolerância e, de outro, o de respeito.

De acordo com Brian Leiter, é possível falar em um genuíno princípio de tolerância:

\begin{abstract}
quando um grupo (denominado grupo 'dominante') desaprova ativamente o que outro grupo (denominado grupo 'desfavorecido') acredita ou pratica; quando o grupo dominante possui à sua disposição os meios para, de forma eficaz e confiante, alterar ou acabar com as crenças ou práticas do grupo desfavorecido; e, ainda assim, o grupo dominante reconhece que existem razões morais ou epistemológicas (ou seja, razões pertencentes ao conhecimento ou à verdade) para permitir que o grupo desfavorecido continue com suas crenças ou práticas (LEITER, 2009: p. 6). ${ }^{3}$
\end{abstract}

\begin{tabular}{l}
\hline Cf., por exemplo, RAZ, Joseph. Autonomy, toleration, and the harm principle. In: GAVISON, Ruth. (Ed.). \\
Contemporary legal philosophy: the influence of H. L. A. Hart" com permissão da Oxford University Press; \\
Brian Leiter, "Why tolerate religion?" manuscrito não publicado pelo autor, Simon Blackburn, "Religion \\
and respect", manuscrito não publicado pelo autor, Leslie Green, "On being tolerated", University of Oxford \\
Faculty of Law Legal Studies Research Paper Series, Working Paper No. 14/2008, entre outros. \\
Cf., por exemplo, BIELEFELDT, Heiner. Filosofia dos direitos humanos: fundamentos de um ethos de \\
liberdade universal. São Leopoldo: Unisinos, 2000 e NUSSBAUM, Martha C. Liberty of Conscience. In: \\
DEFENSE of America's Tradition of Religious Equality. New York: Basic Books, 2008, entre outros. \\
Tradução livre da autora: "where one group (call it the 'dominant' group) actively disapproves of what
\end{tabular} 
Neste sentido, o autor apresenta três argumentos para a tolerância de opiniões e práticas religiosas, os quais estão divididos em duas grandes classes: argumentos morais e epistemológicos.

O primeiro argumento moral examinado é deontológico, ilustrado pelo pensamento de John Rawls, de acordo com o qual a tolerância é uma conseqüência do princípio da igual liberdade de consciência (cf. LEITER, 2009: 7-8). O segundo argumento moral analisado é consistente com a tradição utilitarista. De acordo com este argumento, a tolerância é necessária para maximizar o bem estar humano que resultaria da garantia de um espaço privado onde os indivíduos poderiam livremente decidir "o que acreditar e como viver" (LEITER, 2009: 9).

Adicionalmente aos argumentos morais, Leiter apresenta, baseado nas idéias de John Stuart Mill, argumentos epistemológicos para a tolerância. Em termos gerais, estes argumentos focam na importância da tolerância para o conhecimento e para a descoberta da verdade. As principais suposições desses argumentos são que a verdade contribui à valiosa finalidade moral da utilidade e que a tolerância "de crenças e práticas divergentes contribui para o conhecimento da verdade" (LEITER, 2009: 10). ${ }^{4}$

Leiter conclui - após examinar se a religião é especial do ponto de vista do princípio da tolerância (cf. Leiter, 2009: 14-26) - que os argumentos mencionados acima para a tolerância justificam a proteção legal da liberdade de consciência, que abrange a tolerância de crenças religiosas. Entretanto, o autor entende que não há nenhuma razão moral para destacar questões religiões das demais questões de consciência a fim de lhe dar proteção legal especial (cf. LEITER, 2009: 32).

De acordo com Joseph Raz, há um argumento para a tolerância que decorre da suposição - que ele não aceita - que para os governos respeitarem a autonomia individual, esses não devem adotar nenhuma concepção sobre a vida boa. Neste sentido, o respeito pela autonomia dos indivíduos requereria um princípio de tolerância que exige a exclusão de ideais da política. Em outras palavras, a tolerância em estados liberais requereria o anti-perfectionismo (cf. RAZ, 1987: 155-156). Entretanto, o autor entende que o princípio da tolerância baseado na autonomia individual fornece a fundação moral

another group (call it the 'disfavored' group) believes or does; where that dominant group has the means at its disposal to effectively and reliably change or end the disfavored group's believes or practices; and yet still the dominant group acknowledges that there are moral or epistemic reasons (that is, reasons pertaining to knowledge or truth) to permit the disfavored group to keep on believing and doing what it does."

4 A esse respeito, Celso Lafer, com base no pensamento de Norberto Bobb io, entende que "a tolerância pode ser sustentanda tanto pelo critério ético do respeito pela singularidade do Outro, quanto pela avaliação epistemológica de qual a verdade não é una, mas tem múltiplas faces" (LAFER, 2007). Para entender a visão de Bobbio sobre a tolerância, vide BOBBIO, Norberto. Tolerância e verdade. Elogio da serenidade e outros escritos morais. Tradução de Marco Aurélio Nogueira. São Paulo: UNESP, 2002. p. 149-155. 
para o princípio do dano - que é considerado a única base para o uso de poder coercitivo pela lei - não para o anti-perfectionismo.

Raz argumenta que "um compromisso com a autonomia envolve o compromisso com o pluralismo moral" (RAZ, 1987: 157), ${ }^{5}$ que, de acordo com o autor, deve ser compreendido como a visão de que "há várias formas e vários estilos de vida que exemplificam virtudes diferentes e que são incompativeis" (RAZ, 1987: 159). ${ }^{6}$ Ele sustenta que

o pluralismo moral competitivo do tipo que é necessário para o respeito pela autonomia gera conflitos entre pessoas que buscam valiosas, mas incompatíveis formas de vida. Dada a necessidade de tornar disponíveis tais formas de vida a fim de garantir a autonomia, faz-se necessário restringir as ações e as atitudes das pessoas em tais conflitos por meio do princípio da tolerância. O dever de tolerar é um aspecto do dever de respeito pela autonomia (RAZ, 1987: 165). ${ }^{7}$

Assim, de acordo com Raz, a fim de respeitar a autonomia individual, é necessário adotar um princípio de tolerância que consista na

restrição de uma atividade provavelmente indesejável ao seu receptor ou de uma inclinação de assim agir que é em si mesma moralmente valiosa e que é baseada em um desagrado ou em um antagonismo dessa pessoa ou de uma característica de sua vida, refletindo um julgamento de que esses representam limitações ou deficiências no outro, com a finalidade de deixar que o outro tenha sua maneira ou para que ele ganhe ou mantenha alguma vantagem. (Como indicado a mim por P. M. S. O Hacker, a compaixão é às vezes um exemplo especial de tolerância. Um indivíduo pode tolerar a partir da compaixão.) (RAZ, 1987: 163).8/9

\footnotetext{
Tradução livre da autora: "a commitment to autonomy entails commitment to moral pluralism"

6 Tradução livre da autora: "there are various forms and styles of life which exemplify different virtues and which are incompatible"

7 Tradução livre da autora: "competitive moral pluralism of the kind which is required by respect for autonomy generates conflicts between people pursuing valuable but incompatible forms of life. Given the necessity to make those forms of life available in order to secure autonomy there is a need to curb people's actions and their attitudes in those conflicts by principles of toleration. The duty of toleration is an aspect of the duty of respect for autonomy"

8 Tradução livre da autora: "the curbing of an activity likely to be unwelcome to its recipient or of an inclination so to act which is in itself morally valuable and which is based on a dislike or an antagonism of that person or of a feature of his life, reflecting a judgment that these represent limitations or deficiencies in him, in order to let that person have his way or in order for him to gain or keep some advantage. (As pointed out to me by P. M. S. Hacker, mercy is sometimes a special case of toleration. One can tolerate out of mercy.)"

9 Nesse sentido, Raz argumenta que a "[t]olerância implica na supressão ou na contenção de uma inclinação ou desejo de perseguir, molestar, causar dano ou reagir de uma maneira indesejada a uma pessoa" (RAZ, 1987: 162) (tradução livre da autora: "[t]oleration implies the suppression or containment of an inclination or desire to persecute, harass, harm, or react in an unwelcome way to a person.").
} 
Também sustentando a abordagem da tolerância - em oposição à abordagem do respeito -, Simon Blackburn argumenta que não há nenhuma razão para que alguém respeite um sistema de crenças que esta pessoa não compartilhe (cf. BLACKBURN, 2009: 1). Ele entende que a palavra "respeito" pode significar a simples ausência de interferência, mas que também pode significar admiração, reverência ou deferência (cf. BLACKBURN, 2009: 2). De acordo com estes níveis, o autor afirma que as pessoas podem respeitar outras pessoas que possuam crenças falsas ou irracionais somente num sentido mínimo de tolerância. ${ }^{10}$ Uma vez que nós reconhecemos aquelas crenças como falsas ou irracionais, não é possível respeitá-las, pelo menos não como decorrência do fato de que alguém acredita nelas (cf. BLACKBURN, 2009: 3 e 7). Em conformidade com Blackburn:

acreditar numa crença falsa não concede a ninguém o direito ao respeito. Na medida em que eu não posso compartilhar de sua crença, eu não tenho nenhuma razão para respeitá-lo por acreditar nela - pelo contrário, na verdade (BLACKBURN , 2009: 16). ${ }^{11}$

O autor argumenta que é inconsistente com qualquer concepção apropriada de crença - a qual implica que há um contraste entre certo e errado - pensar que essa é uma questão exclusivamente pessoal e que qualquer crença é tão boa quanto qualquer outra. Na verdade, ele nega que crenças estejam livres de controle normativo e que a desigualdade entre crenças seja uma violação de direitos de uma pessoa. Para ele, "ninguém por um momento acredita nesta igualdade promíscua de crenças na vida quotidiana" (BLACKBURN 2009: 3). ${ }^{12}$

Parece que Blackburn está criticando uma concepção de respeito para crenças religiosas que signifique a admiração de todas as crenças apenas porque elas são detidas por uma pessoa. Entretanto, o respeito requerido pela liberdade religiosa não corresponde a um sentimento de admiração pelas crenças e práticas religiosas específicas as quais nós podemos não compartilhar, mas a um respeito pela capacidade potencial de todos os seres humanos de fazerem escolhas autonomamente, conforme será demonstrado pela abordagem de Martha Nussbaum.

O problema fundamental com o princípio da tolerância é que este deixa o tolerado desconfortável em pelo menos três maneiras (cf. GREEN, 2008: 4-8). Como demonstrado por Leslie Green, a tolerância é limitada em seu escopo, é incompleta e

10 Para o autor, existe também uma graduação de respeito referente a pessoas que possuem crenças falsas, no sentido de que respeitamos mais algumas pessoas das quais discordamos do que outras (cf. BLACKBURN, 2009: 6).

1 Tradução livre da autora: "holding a false belief does not give anyone a title to respect. Insofar as I cannot share your belief, I have no reason to respect you for holding it - quite the reverse, in fact."

12 Tradução livre da autora: "nobody for a moment believes in this promiscuous equality of belief in everyday life." 
parcial, e pode ser considera principalmente como questão de descriminalização de condutas. ${ }^{13 / 14}$ Mas não somente o escopo do princípio da tolerância pode estar errado, seus fundamentos também podem: um princípio de tolerância pode ser adotado por razões morais suspeitas. ${ }^{15}$ Além disso, se um princípio de tolerância for sustentado da maneira errada - aqueles que toleram deixam claro que prefeririam não ser tolerantes -, aqueles que são tolerados podem também sentir-se desconfortáveis (GREEN, 2008: 6-7). ${ }^{16}$

Entretanto, mesmo que um sistema legal pudesse construir um princípio de tolerância que superasse as falhas mencionadas acima, aqueles que são tolerados ainda se sentiriam desconfortáveis porque seria sempre melhor se não tivessem que ser tolerados e sujeitados ao poder de tolerância de outra pessoa (GREEN, 2008: 6-7). ${ }^{17}$ Nesse sentido, Green sustenta que:

Quem quer viver da graça e do favor dos poderosos? Isto é especialmente verdadeiro quando tolerados não têm nenhum poder similar sobre seus toleradores. A esse respeito, a tolerância compartilha algo com outras relações desejáveis, mas assimétricas, como oferecer misericórdia ou sentir piedade, que pode também ser incômoda para seus

13 Em relação à tolerância de minorias sexuais, Leslie Green ressalta que "exceto pela descriminalização há pouca evidência que a não-conformidade sexual seja amplamente tolerada nos Estados Unidos, onde eleições ainda podem ser perdidas ou ganhas dependendo da questão a respeito do que fazer sobre gays e onde, em áreas como direito do trabalho e de família, minorias sexuais continuam a vivenciar tratamento duro atualmente raro em democracias liberais" (GREEN, 2008: 5) (tradução livre da autora: "apart from decriminalization there is slim evidence that sexual non-conformity is widely tolerated in the United States, where elections can still be won or lost on the issue of what to do about the gays and where, in areas from employment to family law, sexual minorities continue to experience harsh treatment now rare in liberal democracies").

14 Não obstante, o autor alerta que a descriminalização de condutas pode não resultar da adoção de um princípio de tolerância - faz-se necessário examinar as razões pelas quais determinada conduta foi descriminalizada (cf. GREEN, 2008: 5).

15 Por exemplo, o autor afirma que "seria preocupante se um governo tolerasse o ato de fumar porque seus atuários descobriram que fumantes morrem mais cedo o suficiente para aumentar o saldo líquido da previdência" (tradução livre da autora). Ademais, ele menciona que se a homossexualidade é tolerada somente porque e na medida em que existem outras condutas mais seriamente erradas para reprimir, gays americanos justamente sentiriam um mal-estar (cf. GREEN, 2008: 6) (tradução livre da autora).

16 Identificando também os problemas decorrentes do princípio da tolerância, Miguel Reale Júnior (2008: 176), com base nas ideias de Javier Lucas, afirma que "a retórica da tolerância não acolhe a criação de uma cultura fruto do diálogo intercultural e ignora os problemas de inclusão do diferente para se estabelecer a 'igualdade na diversidade" " Nesse sentido, Reale Junior defende que o conceito liberal de tolerância deve ser complementado com o conceito social de solidariedade, destacando que "solidariedade significa não apenas aceitação da diferença, mas, como realça Judith Martins-Costa uma aceitação qualificada, de cunho normativo, pela qual se admite que o diferente pode receber maior tutela ou tutela específica que 'atenda à sua diferença concreta', como membro da comunidade" (REALE JÚNIOR, 2008: 176-177).

17 Em 1791, Thomas Paine notou que "tolerância não é o oposto de intolerância, mas a sua imitação. Ambos são despotismos. Um assume para si o direito de reter a liberdade de consciência, e o outro de concedê-la" (paine, 1791). Madison também chamou a atenção das pessoas para o fato de que a palavra tolerância era muito relutante, "sugerindo benevolência legislativa ao invés de direito" (NUSSBAUM, 2008: 90) (tradução livre da autora) 
receptores. E quando nós consideramos as pessoas não como mônadas, mas como membros de grupos minoritários, então o fato da tolerância pode ser um lembrete infeliz da distribuição de poder social (GREEN, 2008: 10). ${ }^{18}$

Assim, o princípio da tolerância reflete também a diferença de poder entre tolerados e toleradores. $\mathrm{E}$ isto causa, mais uma vez, desconforto nos tolerados no sentido de que estes precisam contar com a benevolência dos poderosos quando o poder é exercido e quando a conduta do tolerado é julgada pelos poderosos (cf. GREEN, 2008: 8-12).

Green entende que, entre as três maneiras que geralmente são chamadas para complementar o princípio da tolerância, quais sejam, aceitação, ${ }^{19}$ reconhecimento ${ }^{20}$ e compreensão, ${ }^{21}$ a última é a adequada. $\mathrm{O}$ autor assinala que uma melhor compreensão pode ampliar a tolerância, pode fazer com que as pessoas tenham menos má vontade, pode mudar a disposição para a tolerância incentivando pessoas a revisitar julgamentos e pode também ser uma boa maneira de evitar razões erradas para a tolerância. Essa complementação pode deixar aqueles que são tolerados mais confortáveis porque eles sabem que os toleradores estão fazendo esforços de boa-fé para compreender. Como consequência, os tolerados sentem que são considerados como parte da convivência humana (cf. GREEN, 2008: 21). Green conclui que

Compreender o que a conduta reprovada significa para o agente, e como se encaixa em uma vida humana, pode fazernos revisitar e às vezes revisar aquele julgamento. Pode complementar a tolerância; pode tornar-nos toleradores melhores, especialmente quando nos dá uma idéia do que é estar na extremidade afiada de uma vareta. Esse tipo da compreensão deixa espaço para discordâncias em torno de valores, e deixa espaço para correção de erros. Não

18 Tradução livre da autora: "Who wants to live by grace and favor of the powerful? This is especially true when the tolerated have no similar power over their tolerators. In this respect, toleration shares something with other desirable but asymmetric relations, like offering mercy or taking pity, which can also be uncomfortable for their recipients. And when we consider people not as monads but as members of minority groups, then the fact of toleration may be an unhappy reminder of the social distribution of power."

19 Se o princípio da tolerância fosse complementado pela aceitação, aqueles que praticam atos ou possuem crenças que são toleradas podem (i) assumir abertamente suas práticas e crenças sem que lhes seja imposta nenhuma consequência adversa ou (ii) demandar acomodação para suas práticas e crenças (cf. GREEN, 2008: 12-15)

20 Se o princípio da tolerância fosse complementado pelo reconhecimento, práticas e crenças seriam toleradas de bom grado até por aqueles que pensam que tais práticas e crenças são supersticiosas, sexistas etc. e aqueles que toleram veriam os tolerados como eles mesmos se veem. Nesse sentido, reconhecimento exige não apenas que os valores do tolerado sejam compartilhados pelos toleradores, mas que a identidade do tolerado seja reconhecida (cf. GREEN, 2008: 15-19).

2) Se o princípio da tolerância fosse complementado pelo entendimento, toleradores "deveriam tentar recriar ou capturar, na medida do possível, o sentido que ações e símbolos têm para seus agentes" (GREEN, 2008: 20-25) (tradução livre da autora: "attempt to capture or recreate, to the extent that we can, the meanings that acts and symbols have for their agents."). 
traz a aceitação ou o reconhecimento. Mas o esforço para compreender afirma nossa convivência com os objetos de nossa tolerância. Sem isso, a tolerância é mais pobre - e mais dura - do que precisaria ser (GREEN, 2008: 27). ${ }^{22}$

Embora Green reconheça as principais falhas do princípio da tolerância, parece que sua complementação por uma atitude compreensiva, como sugerida pelo autor, ainda não é suficiente para garantir a igualdade entre cidadãos e para proteger a dignidade humana em democracias liberais.

Também criticando a abordagem da tolerância, Heiner Bielefeldt argumenta que a crise normativa resultante do pluralismo cultural deve ser endereçada pelo reconhecimento de tal pluralismo, não pela sua tolerância. Como afirmado por Bielefeldt, o problema da tolerância é que aqueles que têm o poder de tolerar também têm o poder de não tolerar, e aqueles que consideram que tem o poder para tolerar pretendem julgar as questões de consciência. $\mathrm{O}$ autor sustenta que somente após a superação dos conceitos tradicionais de tolerância, o pluralismo religioso e político não será considerado uma perda infeliz do centralismo religioso e da cosmovisão da sociedade tradicional. O pluralismo religioso e político serão então considerados uma expressão da responsabilidade autônoma dos seres humanos que desejam ser respeitados em suas convicções e ter direitos iguais (cf. BIELEFELDT, 2000: 50).

Do mesmo modo, Martha Nussbaum argumenta em favor do princípio do respeito pela consciência (Respect-Conscience Principle), ${ }^{23}$ de acordo com o qual a esfera pública deve respeitar os diferentes comprometimentos religiosos de todos os cidadãos e deve garantir um espaço onde os cidadãos possam agir consistentemente com suas consciências, de forma que todos os cidadãos possam entrar no espaço público em condições iguais (NUSSBAUM, 2008: 22-23).

Nussbaum entende que tal princípio não requer a aprovação de reivindicações teológicas e éticas de nenhuma religião pela esfera pública ou por cidadãos individualmente (cf. NUSSBAUM 2008: 23). Neste sentido, ela sustenta que, o "[r] espeito por concidadãos não significa dizer ou acreditar que suas visões religiosas estão corretas, ou mesmo que todas as religiões são caminhos válidos ao entendimento da vida" (NUSSBAUM, 2008: 23). ${ }^{24}$ Assim, ela conclui que

22 Tradução livre da autora: "Understanding what the disapproved conduct means for the agent, and how it fits into a human life, may make us revisit and sometimes revise that judgment. It may supplement torelation; it may make us better tolerators, especially when it gives us a grasp of what it is to be at the sharp end of a particular stick. That kind of understanding leaves room for disagreement in value, and room for correction of error. It does not bring acceptance or recognition. But the effort to understand affirms our fellowship with the objects of our toleration. Without that, toleration is poorer - and harder - than it need to be."

23 A autora expressamente afirma sua preferência pelo termo "respeito" ao invés do termo "tolerância", porque entende que o último é muito fraco e relutante (cf. NUSSBAUM, 2008: 24).

${ }^{24}$ Tradução livre da autora: "[r]espect for fellow citizens does not mean saying or believing that their religious 
"O princípio do respeito pela consciência significa apenas respeitá-los como seres humanos com suas próprias escolhas para fazer em matérias religiosas, e um direito de fazer livremente essas escolhas" (NUSSBAUM, 2008: 23). ${ }^{25}$

Assim, é a faculdade de buscar a finalidade última da vida que tem valor e que deve ser respeitada, independentemente de os indivíduos a estarem usando de forma boa ou ruim. Esta abordagem não implica que encontrar a finalidade última da vida tem valor intrínseco; como resultado, as visões céticas e anti-metafísicas também merecem ser respeitadas (NUSSBAUM, 2008: 168-169).

De acordo com Nussbaum, o Estado não deve endossar nenhuma religião ou a não religião sobre a religião. Em consequência, nenhuma indicação pública de acordo ou desacordo devem ser feitos. As instituições públicas não devem ter conteúdo religioso - embora a autora assuma que terão conteúdo ético - porque elas devem ser fundadas em princípios tais como o igual respeito que todos os cidadãos podem compartilhar independentemente de sua religião (NUSSBAUM, 2008: 23).

Cumpre notar que essa abordagem não implica uma visão pós-modernista ${ }^{26}$ de completa relatividade de valores. Nesse sentido, Nussbaum esclarece que o princípio do respeito pela consciência "não implica que todas as religiões e visões da vida devem ser (igualmente) respeitadas pelo governo" (NUSSBAUM, 2008: 24). ${ }^{27}$ Se uma visão contradiz ou ameaça as fundações da ordem constitucional e a igualdade dos cidadãos, a comunidade pode razoavelmente se opor e desfavorecer tal visão (cf. NUSSBAUM, 2008: 24).

Assim, na linha exposta por Nussbaum, embora como regra geral crenças e práticas religiosas devam ser respeitadas, algumas ações e discursos não farão jus a igual respeito e tratamento se ameaçarem os mais importantes valores da comunidade política, sendo certo que Estados democráticos liberais devem regular e limitar tais ações e discursos.

Alguns autores sugeriram limites a serem impostos por Estados democráticos liberais. Nussbaum, por exemplo, entende que

views are correct, or even that all religions are valid routes to understanding life."

25 Tradução livre da autora: "The Respect-Conscience Principle just means respecting them as human beings with their own choices to make in religious matters, and a right to make those choices freely."

26 Embora não haja consenso sobre seu conteúdo, o termo "pós-modernismo" foi definido a partir de seu uso por Jean Baudrillard, Jean-François Lyotard, Fredric Jameson, entre outros, e é utilizado aqui para designer o contexto histórico e sociológico particular caracterizado pelo paradigma da transição da modernidade, que começou no final do século XX. As principais características do paradigma pós-moderno são a ausência de consenso, o fim das metanarrativas e de qualquer pretensão de teorias universais (cf. BITTAR, 2005: 96). Para uma visão sociológica mais detalhada do pós-modernismo, confira Gisela B. Taschner, "A pósmodernidade e a sociologia", in Revista USP, São Paulo, Coordenadoria de Comunicação Social (CCS) da Universidade de São Paulo, n. 42, jun./ago. 1999 p. 6-19.

27 Tradução livre da autora: "does not imply that all religions and views of life must be (equally) respected by the government." 
Se as pessoas buscam torturar crianças, ou escravizar minorias, citando sua religião como sua razão, deve-se resistir a suas reivindicações mesmo que elas possam ser sinceras. Se eles simplesmente falam em favor da escravidão ou da tortura, sua liberdade de expressão deve ser protegida, até o ponto em que o discurso se transforme em uma ameaça. Eles não poderão, entretanto, apresentar suas idéias na esfera política em bases iguais com outras idéias, uma vez que a Constituição (no caso da escravidão) e a lei criminal (no caso da tortura) proíbem as práticas que eles recomendam (NUSSBAUM, 2008: 24) ${ }^{28}$

De acordo com Jürgen Habermas, as sociedades multiculturais somente podem tolerar tradições que aceitem a discordância razoável, que ele chama de tradições não-fundamentalistas. Habermas entende que somente as formas de vida tolerantes que aceitam a discordância razoável são capazes de coexistir com o reconhecimento dos membros de culturas diferentes (HABERMAS, 1994: 151). ${ }^{29}$ De modo similar, Marcelo Neves argumenta que a intolerância étnica e o fundamentalismo religioso são contra o pluralismo requerido pela esfera pública e devem ser jurídica e politicamente restringidos (NEVES, 2006: 136, 222, 223 e Neves, 2000: 41).

Para Miguel Reale Júnior, o reconhecimento de setores diferentes da sociedade (tais como minorias étnicas ou classes especiais de pessoas), de seus direitos e de suas especificidades - a partir do avanço do conceito liberal de tolerância para o conceito social de solidariedade -, "bem como a assunção da responsabilidade por sua integração social, não importa em abrir mão de valores essenciais da pessoa humana afirmados e conquistados ao longo do processo histórico" (REALE JÚNIOR, 2008: 177). Sustentando que pluralismo não significa "arbitrismo" no sentido de aceitação de qualquer organização social, Reale Júnior (idem: ibidem) destaca que o pluralismo deve ser limitado pelas conquistas essenciais acerca da dignidade humana, conquistas essas que são historicamente impostergáveis.

Com uma abordagem diferente, Will Kymlicka sustenta que os liberais deveriam tentar acomodar grupos não liberais desde que estes não estejam buscando o apoio da sociedade como um todo e não queiram impor seus valores a outros grupos. Para

${ }_{28}$ Tradução livre da autora: "[i]f people seek to torture children, or to enslave minorities, citing their religion as their reason, their claims must be resisted even though they may be sincere. If they simply talk in favor of slavery or torture, their freedom to speak must be protected, up to the point at which speech becomes a threat. They will not, however, be able to present their ideas in the political sphere on an equal basis with other ideas, since the Constitution (in the case of slavery) and the criminal law (in the case of torture) forbid the practices they recommend."

29 Para uma visão completa sobre o entendimento de Habermas a respeito de tolerância religiosa, vide Jürgen Habermas, "Entre naturalismo e religião: estudos filosóficos", tradução de Flávio Beno Siebeneichler, Rio de Janeiro: Tempo Brasileiro, 2007, especialmente Item IV - Tolerância, p. 279-392. 
o autor, a maioria das pessoas entende que, se uma minoria nacional está oprimindo outros grupos, uma intervenção contra a agressão é justificável. Entretanto, se a minoria somente visa guiar sua comunidade de acordo com princípios não liberais e não está interessada em estabelecer regras para outros grupos ou em privar esses outros grupos de seus recursos, parece errado impor valores liberais (cf. KYMLICKA, 1997: 154-155). Assim, Kymlicka adota uma visão de acordo com a qual a tolerância liberal deve proteger os direitos dos indivíduos de discordar de seus grupos, assim como o direito dos grupos de não serem perseguidos pelo Estado, enquanto que o poder de grupos não liberais de restringir a liberdade de seus membros e o poder de Estados não liberais de restringir a liberdade de culto devem ser limitados.

Neste item foram examinados (i) a diferença entre o princípio da tolerância e o princípio do respeito no que se refere à liberdade religiosa e (ii) os limites para a adoção do princípio do respeito por democracias liberais. A partir dessa análise, o ordenamento jurídico brasileiro e a regulação da liberdade religiosa serão estudados no item subsequente.

\section{Liberdade religiosa no Brasil}

A regulação da liberdade religiosa no Brasil é examinada neste item com o intuito de verificar se o ordenamento jurídico brasileiro adota o princípio da tolerância ou do respeito. São analisados os dispositivos da Constituição Federal que tratam da liberdade religiosa, quais sejam, aqueles relacionados ao livre exercício de cultos religiosos, à proteção aos locais de culto e suas liturgias (art. $5^{\circ}$ inc. VI), à garantia de prestação de assistência religiosa a pessoas em estabelecimentos de internação coletiva (art. $5^{\circ}$, inc. VII), à acomodação jurídica em razão de imperativo de consciência (art. $5^{\circ}$ : inc. VIII), à vedação ao estabelecimento de religião pelo Estado (art. 19) e ao ensino religioso facultativo (art. 210), bem como a legislação federal relacionada. O estudo ora realizado não pretende analisar de forma exaustiva as leis estaduais, análise esta que, quando realizada, serve apenas para ilustrar a aplicação das normas constitucionais.

O dispositivo central da Constituição da República Federativa do Brasil de 1988 que serve de base para a proteção da liberdade religiosa é seu art. $5^{\circ}$, o qual estabelece que "[t]odos são iguais perante a lei, sem distinção de qualquer natureza, garantindo-se aos brasileiros e aos estrangeiros residentes no País a inviolabilidade do direito à vida, à liberdade, à igualdade, à segurança e à propriedade" Os dispositivos constitucionais examinados a seguir visam a garantir a observância da liberdade religiosa, que se apresenta como um dos aspectos da liberdade em sentido lato, a qual é constitucionalmente assegurada a todos os brasileiros e estrangeiros residentes no País. 
3.1. Livre exercício de cultos religiosos e vedação ao estabelecimento de religião

O inciso VI do art. $5^{\circ}$ da Constituição Federal determina que "é inviolável a liberdade de consciência e de crença, sendo assegurado o livre exercício dos cultos religiosos e garantida, na forma da lei, a proteção aos locais de culto e a suas liturgias."

Diferentemente do texto atual, a Constituição brasileira de 1967 expressamente limitava, em seu art. 150, parágrafo 5, o exercício da liberdade religiosa aos cultos que não contrariassem a ordem pública e os bons costumes. De acordo com Celso Ribeiro Bastos, embora a atual Constituição omita o requisito de observância da ordem pública e dos bons costumes, está implícito no ordenamento jurídico brasileiro que os direitos devem ser exercidos de modo que não prejudiquem os direitos de outras pessoas e em consonância com os valores éticos e morais em que se funda a sociedade brasileira, independentemente de quão difícil possa ser para os tribunais definirem quais são esses valores, que estão evoluindo constantemente (cf. MARTINS e BASTOS, 1989: 52). Em sentido diverso do entendimento de Bastos, Manuel Gonçalves Ferreira Filho entende que em razão da omissão da Constituição, os cultos religiosos são garantidos inclusive contra eventuais limitações baseadas na ordem pública e nos bons costumes (cf. FERREIRA FILHO, 1990: 33). A interpretação de Ferreira Filho parece mais adequada, uma vez que os legisladores constitucionais omitiram intencionalmente a exigência da observância da ordem pública e dos bons costumes. Dessa forma, os tribunais brasileiros não podem limitar o exercício da liberdade religiosa invocando a ordem pública ou os bons costumes.

Uma questão muito polêmica sobre o exercício da liberdade de culto e sua limitação no Brasil é relacionada à caracterização do crime de "curandeirismo" previsto no art. 284 do Código Penal. ${ }^{30}$ Enquanto alguns autores, por exemplo, Magalhães Noronha, sustentam que uma prática religiosa que pretenda curar, sem título ou habilitação apropriada, seja enquadrada como "curandeirismo" (NORONHA, 1968: 107), outros autores, como Francisco de Assis Toledo, argumentam que os rituais espíritas e os rituais de todas as outras religiões, tais como o Catolicismo, o Protestantismo ou Budismo, embora possam visar à cura ou à diminuição do sofrimento de pessoas doentes, nunca poderão ser considerados um crime (cf. TOLEDO, 1986: 100-101). Francisco de Assis Toledo parece estar certo em sua interpretação do crime "curandeirismo" uma vez que ele leva a sério a

Artigo 284. Exercer o curandeirismo:

I - prescrevendo, ministrando ou aplicando, habitualmente, qualquer substância;

II - usando gestos, palavras ou qualquer outro meio;

III - fazendo diagnósticos:

Pena - detenção, de seis meses a dois anos.

Parágrafo único - Se o crime é praticado mediante remuneração, o agente fica também sujeito à multa. 
garantia constitucional da liberdade de religião. Atualmente, o poder judiciário no Brasil entende que os rituais espíritas relacionados à cura de pessoas doentes não podem ser considerados "curandeirismo" sendo constitucionalmente protegidos como um tipo de culto. ${ }^{31}$

Cumpre notar que, durante o período do Império no Brasil, havia uma liberdade religiosa sem liberdade de culto: somente o culto católico era reconhecido como livre. Outras religiões somente podiam celebrar seus cultos na esfera doméstica, sendo proibido todo o templo fora do lar para outras religiões (cf. MARTINS e BASTOS, 1989: 50 e CRETELLA JÚNIOR, 1992: 252).

Essa abordagem inicial da liberdade religiosa no ordenamento jurídico brasileiro pode ser explicada como consequência de nosso passado colonial. Uma das justificações ideológicas subjacentes à colonização do Brasil por Portugal - e de outros países da América Latina pela Espanha - era relacionada à catequização dos povos indígenas. Como resultado, o catolicismo foi a religião oficial até o fim do período imperial. ${ }^{32}$

A esse respeito, vale notar, com Fábio Konder Comparato (2001: 312), que "não há autêntica liberdade de crença e de opinião, num Estado que adota uma religião oficial. As pressões de toda a sorte - políticas, econômicas e profissionais - contra os não seguidores da religião de Estado tornam essa liberdade ilusória." Com efeito, as religiões indígenas e africanas e seus valores foram negados durante grande parte da história do Brasil e ainda hoje há na sociedade brasileira preconceito contra tais religiões. ${ }^{33}$

Exemplificativamente, destaque-se que, em 1985, o Supremo Tribunal Federal arquivou a Representação n. 959-PB, que questionava uma lei do Estado da Paraíba de 1966 de acordo com a qual os cultos africanos deveriam obter uma licença prévia para iniciar suas atividades. Tal licença seria concedida se, entre outras exigências, o responsável pelos cultos pudesse provar sua idoneidade moral e perfeitas condições de saúde mental, conforme documentado em relatório psiquiátrico. A ação arquivada com

31 STF, RHC 62.240/SP, rel. Min. Francisco Rezek, $2^{\mathrm{a}}$ Turma, 13/12/1984, DJ 02/08/1985, p. 12046 e STJ, HC 1498/RJ, rel. Min. Luiz Vicente Cernicchiaro, 6a Turma, j. 18/12/1992, DJ 1, de 16/08/1993, p. 15994. Cf. também FERREIRA, Pinto. Comentários à constituição brasileira. São Paulo: Saraiva, 1989. p. 71.

32 Com efeito, Celso Lafer nos lembra que "incumbia ao imperador, antes de ser proclamado, jurar manter a religião católica, cabendo-lhe em contrapartida, entre as suas atribuições, nomear bispos e prover os benefícios eclesiásticos, bem como conceder ou negar beneplácitos a atos da Santa Fé (cf. Constituição de 1824 , art. $5^{\circ}, 102$, parágrafos $2^{\circ}$ e $14 ; 103$ )" (LAFER, 2007).

33 Note-se que a negação dos valores africanos e de uma identidade africana no Brasil abrangendo a esfera religiosa tem suas origens na chegada dos escravos africanos desde o século XVI. A relação entre os povos africanos e a sociedade colonial foi caracterizada pela conversão compulsória dos escravos à religião de seus donos e pela perseguição daqueles que insistissem na manutenção das práticas ancestrais (D'ADESKY, 2005: 51-52). 
base no fato de que a lei em questão havia sido modificada em 1977, tendo sido excluída a exigência da licença prévia.

A separação entre o Estado e a Igreja foi estabelecida no Brasil somente durante a República pelo Decreto n. 119-A, datado de 7 de janeiro de 1890, de autoria de Rui Barbosa (cf. LAFER, 2007), que proibiu a intervenção do governo federal e dos estados em questões religiosas e estabeleceu a liberdade de culto. ${ }^{34}$ Desde então, o Brasil é um estado laico. A separação entre Estado e Igreja na Constituição de 1988 está prevista no art. 19:

É vedado à União, aos Estados, ao Distrito Federal e aos Municípios: (i) estabelecer cultos religiosos ou igrejas, subvencioná-los, embaraçar-lhes o funcionamento ou manter com eles ou seus representantes relações de dependência ou aliança, ressalvada, na forma da lei, a colaboração de interesse público (...).

Consequentemente, o Estado brasileiro é indiferente às várias igrejas que podem ser livremente formadas como entidades legais. O Estado deve ser absolutamente neutro, sendo proibida a discriminação entre igrejas para beneficiá-las ou prejudicá-las. Também não pode impor nenhum ônus indevido à formação de igrejas. Na realidade, há mesmo um incentivo constitucional para sua formação que resulta da imunidade tributária a que fazem jus (MARTINS e BASTOS, 1989: 50-51). ${ }^{35}$

Observe-se que a colaboração no interesse público mencionada no Artigo 19, para não infringir a proibição de estabelecimento de religião pelo Estado, não pode ocorrer em um campo fundamentalmente religioso (cf. FERREIRA FILHO, 1990: 144, CRETELLA JUNIOR, 1992: 1179 e LAFER, 2007). Não obstante, essa disposição tem implicações muito complexas quando se trata de sua execução: como é possível estabelecer a colaboração no interesse público entre o Estado e uma determinada igreja sem favorecer uma religião sobre a outra $?^{36}$ Ademais, essa disposição levanta um problema similar ao que resulta da assistência religiosa a pessoas em estabelecimentos de internação coletiva e do ensino religioso facultativo em escolas, conforme detalhado abaixo: é possível, na prática, ensinar religião, prestar assistência religiosa e estabelecer esquemas de colaboração

\footnotetext{
34 Esse decreto nunca foi expressamente revogado. Cf. <https://legislacao.planalto.gov.br/LEGISLA Legislacao.nsf/fraWeb? OpenFrameSet\&Frame $=$ frmWeb2\&Src $=\% 2$ FLEGISLA $\% 2 F L$ egislacao.nsf $\% 2 \mathrm{Fvi}$ wTodos $\% 2 \mathrm{Fbea39c8e} 0 \mathrm{e} 484811032569 \mathrm{fa} 005 \mathrm{afab} 4 \% 3 \mathrm{FOpenDocument} \% 26 \mathrm{Highlight} \% 3 \mathrm{D} 1 \% 2 \mathrm{C} \% 26$ Auto Framed $>$. Acesso em: 3 abr. 2009.

35 Cumpre notar que a Lei n. 8.245 , datada de 18 de outubro de 1991, conforme alterada, estabelece que o contrato de locação de imóveis utilizados por entidades religiosas devidamente registradas, bem como por hospitais, unidades sanitárias oficiais, asilos, estabelecimentos de saúde e de ensino autorizados e fiscalizados pelo Poder Público, somente poderá ser rescindido em determinadas situações.

36 Para uma crítica sobre a exceção relacionada à colaboração no interesse público, vide CRETELLA JÚNIOR, 1992: 1180.
} 
no interesse público sem favorecer uma determinada religião e sem violar o art. 19 da Constituição?

\subsection{Garantia de assistência religiosa em estabelecimentos de internação coletiva}

A Constituição brasileira garante a prestação de assistência religiosa a pessoas em estabelecimentos de internação coletiva, abrangendo presos, militares e pacientes hospitalizados (cf. MARTINS e BASTOS, 1989: 54). De acordo com o inciso VII do art. $5^{\circ}$ da Constituição, "é assegurada, nos termos da lei, a prestação de assistência religiosa nas entidades civis e militares de internação coletiva." O caráter laico do Estado brasileiro não é afetado por esta disposição, uma vez que o Estado não é obrigado a prestar assistência religiosa e as entidades religiosas é que irão prestá-la (cf. MARTINS e BASTOS, 1989: 51 e 54 e FERREIRA FILHO, 1990: 34).

Neste sentido, a Lei n. 7.210, de 11 de julho de 1984, que trata da execução penal, estabelece em seu art. 10 que o Estado deve prestar assistência aos presos e internados, incluindo os egressos, objetivando prevenir o crime e orientar o retorno à convivência em sociedade. Tal assistência consistirá, de acordo com o art. 11, em assistência material, à saúde, jurídica, educacional, social e religiosa. De fato, o art. 41 estabelece que tais assistências são direitos dos presos.

De acordo com o art. 24, "a assistência religiosa, com liberdade de culto, será prestada aos presos e aos internados, permitindo-se-lhes a participação nos serviços organizados no estabelecimento penal, bem como a posse de livros de instrução religiosa" O primeiro parágrafo deste artigo estabelece que haverá local apropriado para os cultos religiosos no estabelecimento penal; o segundo parágrafo dispõe que "nenhum preso ou internado poderá ser obrigado a participar de atividade religiosa"

Adicionalmente, a Lei n. 9.982, de 14 de julho de 2000, que trata da prestação de assistência religiosa em estabelecimentos prisionais civis e militares e em entidades hospitalares públicas e privadas, garante em seu art. $1^{\circ} \mathrm{o}$ acesso aos religiosos de todas as confissões "aos hospitais da rede pủblica ou privada, bem como aos estabelecimentos prisionais civis ou militares, para dar atendimento religioso aos internados, desde que em comum acordo com estes, ou com seus familiares no caso de doentes que já não mais estejam no gozo de suas faculdades mentais." Vale notar que, nos termos do art. $2^{\circ}$ "os religiosos chamados a prestar assistência nas entidades definidas no art. $1^{\circ}$ deverão, em suas atividades, acatar as determinações legais e normas internas de cada instituição hospitalar ou penal, a fim de não pôr em risco as condições do paciente ou a segurança do ambiente hospitalar ou prisional" 
Duas disposições dessa lei foram vetadas pelo Presidente. ${ }^{37}$ A primeira disposição estabelecia que a prestação de assistência religiosa não seria permitida se, de acordo com o hospital ou a prisão, houvesse risco de vida ou saúde para o internado ou para o religioso. O Presidente justificou esse veto argumentando que a transferência do processo decisório relativo à prestação de assistência religiosa aos hospitais ou prisões excluindo-se o paciente ou preso, bem como suas famílias, era contrário aos incisos VI e VII do art. $5^{\circ}$ da Constituição. Ademais, o Presidente sustentou que a precaução que motivou o dispositivo vetado já está assegurada pelo art. $2^{\circ}$ da lei em questão.

A segunda disposição vetada pelo Presidente determinava que o interno teria direito a, pelo menos, uma visita semanal de religiosos da confissão religiosa que professe. O Presidente justificou esse veto argumentando que a periodicidade das visitas deveria ser determinada pela autoridade local levando em consideração as particularidades regionais, os usos e costumes. Além disso, o Presidente sustentou que era inadequado tratar hospitais e prisões da mesma forma, tendo em vista as circunstâncias específicas de cada instituição. Havia também a preocupação de que o número mínimo de visitas estabelecido por lei se tornasse o número máximo permitido na prática.

\subsection{Acomodação em razão de imperativo de consciência}

Nos termos do inciso VIII do art. $5^{\circ}$ da Constituição, "ninguém será privado de direitos por motivo de crença religiosa ou de convicção filosófica ou política, salvo se as invocar para eximir-se de obrigação legal a todos imposta e recusar-se a cumprir prestação alternativa, fixada em lei" Esse inciso, entre outras coisas, está relacionado ao serviço militar obrigatório estabelecido pelo art. 143 da Constituição. O parágrafo $1^{\circ}$ deste artigo dispõe que "às Forças Armadas compete, na forma da lei, atribuir serviço alternativo aos que, em tempo de paz, após alistados, alegarem imperativo de consciência, entendendose como tal o decorrente de crença religiosa e de convicção filosófica ou política, para se eximirem de atividades de caráter essencialmente militar" 38

Esse é um dos casos de acomodação existentes no ordenamento jurídico brasileiro relacionado à crença religiosa ou às convicções filosóficas ou políticas. Para buscar proteção constitucional de modo a não participar do serviço militar compulsório em tempos de paz, faz-se necessário provar comprometimento com ideias não beligerantes a ser demonstrado por atitudes passadas que estejam em consonância com tal ideal (MARTINS e BASTOS, 1989: 56). Note-se que é possivel ser excluído de atividades essencialmente militares, mas poderão ser impostos serviços alternativos que consistam em

\footnotetext{
37 Cf. "Mensagem de Veto n. 960, de 14 de julho de 2000" Disponível em: <https://www.planalto.gov.br/ ccivil_03/leis/Mensagem_Veto/2000/Mv0960-00.htm>. Acesso em: 13 fev. 2009.

38 Esse dispositivo constitucional foi regulamentado pela Lei n. 8.239, de 4 de outubro de 1991.
} 
atividades administrativas, de assistência, filantrópicas ou produtivas, ${ }^{39}$ já que a obrigação de servir ao País não é excluída (MARTINS e BASTOS, 1989: 211). Cumpre notar que da reivindicação de imperativo de consciência não pode resultar a privação de direitos exceto se a pessoa também se recusar a prestar serviço alternativo não essencialmente militar. Nessas circunstâncias, a Constituição e a legislação aplicável não são inteiramente claras sobre as consequências legais da recusa. Alguns autores entendem que nesse caso a pessoa que se recusou a prestar serviços alternativos poderia ser privada de direitos (FERREIRA FILHO, 1994: 34 e 81 e MARTINS e BASTOS, 1989: 212). ${ }^{40}$

Constata-se aqui o que parece ser uma grande incoerência no ordenamento jurídico brasileiro. Enquanto em tempos de paz as pessoas podem reivindicar imperativo de consciência para evitar serviços essencialmente militares, quando o Estado declara guerra, nenhum cidadão poderá invocar crenças religiosas ou convicções filosóficas ou políticas com a finalidade de não participar do serviço militar. ${ }^{4 l}$ Como resultado, durante o período mais adequado e apropriado para expressar desacordo com guerras e ideais beligerantes, as pessoas não tem direito de reivindicar imperativo de consciência para não participar do serviço militar, na hipótese de a Constituição ser interpretada literalmente.

Outro caso de acomodação relacionado a crenças religiosas que vale ser mencionado é o uso terapêutico do chá Ayahuasca em rituais religiosos. A partir de 1985, o governo brasileiro começou a estudar os aspectos sociais e culturais referentes ao uso de tal chá. Em 23 de novembro de 2006, o Grupo Multidisciplinar de Trabalho do Comitê Nacional Antidrogas do Sistema Nacional de Políticas Públicas sobre Drogas ${ }^{42}$ emitiu seu relatório final reconhecendo que o uso do chá Ayahuasca deveria ser limitado a rituais religiosos, em locais autorizados pela direção das entidades que fazem uso de tal chá, sendo proibido seu uso em conjunto com substância ilegais. Atualmente, o uso do chá Ayahuasca, em conformidade com as normas aplicáveis, é assegurado com base na garantia constitucional da liberdade de consciência e de crença e do livre exercício de cultos religiosos. Ademais, a legitimidade do uso religioso da Ayahuasca foi ratificada como "rica e ancestral manifestação cultural que, exatamente pela relevância de seu valor

39 Os serviços alternativos podem ser prestados em organizações militares da ativa e em órgãos de formação de reservas das Forças Armadas ou em órgãos subordinados aos Ministérios Civis, mediante convênios entre estes e os Ministérios Militares. Cf. $\S \S 2^{\circ}$ e $3^{\circ}$ do art. $3^{\circ}$ da Lei n. 8.239, de 4 de outubro de 1991.

40 No entanto, parece-nos que o serviço militar obrigatório não está de acordo com os princípios que norteiam a Constituição, no sentido de que serviços alternativos não deveriam ser impostos. Contudo, a discussão sobre o serviço militar obrigatório no Brasil ultrapassa o escopo deste artigo.

4I Ives Granda Martins sustenta que em tempos de guerra, todos os cidadãos têm iguais deveres perante o País (cf. MARTINS e BASTOS, 1989: 212). Discordamos totalmente deste posicionamento porque uma das formas mais eficazes de expressar desacordo com guerras e ideais beligerantes é durante o período de guerra, quando as pessoas que não concordam poderiam recusar-se a prestar serviços militares. Contudo, conforme mencionado acima, a discussão sobre o serviço militar obrigatório no Brasil ultrapassa o escopo deste artigo.

42 O Sistema Nacional de Políticas Públicas sobre Drogas - SISNAD foi instituído pela Lei n. 11.343, de 23 de agosto de 2006. 
histórico, antropológico e social, é credora da proteção do Estado, nos termos do art. $2^{\circ}$ caput, da Lei n. 11.343/06 e do art. $215, \S 1^{\circ}$ da CF" ${ }^{43}$ que dispõe que "[o] Estado protegerá as manifestações das culturas populares, indígenas e afro-brasileiras, e das de outros grupos participantes do processo civilizatório nacional" 44

É de se notar tarnbém o recente caso no Estado de São Paulo de acomodação religiosa previsto na Lei Estadual n. 13.541, de 7 de maio de 2009. Tal lei proíbe o consumo de cigarros, cigarrilhas, charutos, cachimbos ou de qualquer outro produto fumígeno, derivado ou não do tabaco, em ambientes de uso coletivo, públicos ou privados. Contudo, nos termos do art. $6^{\circ}$ da referida lei, essa não se aplica aos locais de culto religioso em que o uso de produto fumígeno faça parte do ritual. Ou seja, trata-se de mais um caso em que uma lei geral é excetuada para acomodar práticas relacionadas à liberdade de religião e de culto.

Diferentemente das situações envolvendo serviço militar obrigatório, o chá Ayahuasca e rituais religiosos que envolvem o uso de produtos fumígenos, foi negada acomodação quando da reivindicação de imperativo de consciência no contexto de frequência escolar no Estado de São Paulo. Em opinião escrita por Ada Pellegrini Grinover, publicada em 25 de outubro de 2002, o Conselho Estadual de Educação do Estado de São Paulo entendeu que estudantes que fossem membros da Igreja Adventista do Sétimo Dia estariam obrigados a frequentar as aulas durante o período compreendido entre 18:00 horas de sexta-feira e 18:00 de sábados, de acordo com a Lei n. 9.394, de 20 de dezembro de 1996, conforme alterada, embora tal frequência seja contrária às suas práticas religiosas, uma vez que não há prestação alternativa estabelecida em lei para tal escusa de consciência, conforme fixado pelo inciso VIII do art. $5^{\circ}$ da Constituição..$^{45}$

Adicionalmente aos casos de acomodação em razão de imperativo de consciência, o inciso VIII do art. $5^{\circ}$ da Constituição também já foi invocado para proteger os direitos dos professores do Estado de Rio de Janeiro contra lei estadual que estabeleceu que somente os professores credenciados pela autoridade religiosa competente estarão autorizados a ministrar as aulas de ensino religioso em escolas públicas estaduais. Para compreender a Ação Direta de Inconstitucionalidade - ADIN n. 3.268/04 que ainda não foi decidida pela Suprema Corte faz-se necessário analisar as disposições legais aplicáveis relacionadas ao ensino religioso no Brasil.

43 Cf. Relatório Final do Grupo Multidisciplinar de Trabalho, disponível, entre outros sítios, em <http:/ www.santodaime.org/comunidade/noticias/relfinal_conad.htm>. Acesso em: 4 mar. 2009 e <http://www. ayahuascabrasil.org/index.php?op=legis 101:. Acesso em: 4 mar. 2009.

44 A acomodação relacionada ao uso do chá Ayahuasca para fins religiosos nos Estados Unidos foi decidida pela Suprema Courte em Gonzales v. O Centro Espirita Beneficente União do Vegetal, 546 U.S. 418 (2006).

45 Cf. "Parecer CEE No. 442/2002 - CES - Aprovado em 23/10/2002". Disponivel em: <http://www.ceesp. sp.gov.br/Pareceres/pa_442_02.htm>. Acesso em: 4 mar. 2009. 


\subsection{Ensino religioso facultativo}

Nos termos do art. 210 da Constituição, "[s]erão fixados conteúdos mínimos para o ensino fundamental, de maneira a assegurar formação básica comum e respeito aos valores culturais e artísticos, nacionais e regionais." O parágrafo $1^{\circ}$ desse Artigo dispõe que "[o] ensino religioso, de matrícula facultativa, constituirá disciplina dos horários normais das escolas públicas de ensino fundamental"

Nesse sentido, o art. 33 da Lei n. 9.394, de 22 de julho de 1997, conforme alterada, determina que o respeito à diversidade cultural religiosa do Brasil é assegurado no ensino religioso, sendo proibida qualquer forma de proselitismo. O primeiro parágrafo desse Artigo dispõe que "[o]s sistemas de ensino regulamentarão os procedimentos para a definição dos conteúdos do ensino religioso e estabelecerão as normas para a habilitação e admissão dos professores" Ademais, de acordo com o segundo parágrafo do referido Artigo, "[o]s sistemas de ensino ouvirão entidade civil, constituída pelas diferentes denominações religiosas, para a definição dos conteúdos do ensino religioso" 46

De modo a observar a proibição constitucional de estabelecimento de religião, o ensino religioso em escolas não pode consistir no ensino de uma religião determinada. Nesse sentido, a previsão constitucional tem por finalidade dar oportunidade a estudantes que estão em idade de formação de personalidade de ter acesso a informações de modo que no futuro eles possam livremente escolher adotar ou não adotar uma religião (cf. SCHERKERKEWITZ, 2002: 60). ${ }^{47}$

Levando em consideração esses dispositivos, a ADIN n. 3.268/04 foi ajuizada pela Confederação Nacional dos Trabalhadores em Educação com o intuito de declarar que a Lei n. 3.459, aprovada pela Assembleia Legislativa do Estado do Rio de Janeiro em 14 de setembro de 2000, é inconstitucional uma vez que estabeleceu que (i) religião seria ensinada na forma confessional, (ii) o conteúdo do ensino religioso seria atribuição de diversas autoridades religiosas e (iii) apenas professores credenciados pela autoridade religiosa competente poderiam ensinar religião em escolas oficiais.

A Confederação Nacional dos Trabalhadores em Educação argumenta que o ensino religioso na forma confessional viola o art. 210 da Constituição, que estabelece que os valores culturais serão respeitados quando do estabelecimento dos conteúdos mínimos para o ensino fundamental, e o art. 33 da Lei Federal n. 9.394/97, que determina que o ensino religioso respeitará a diversidade cultural do Brasil.

46 Cumpre notar que, nos termos do art. 21 do Decreto-Lei n. 4.244, de 9 de abril de 1942, o programa e o regime didático do ensino religioso deveria ser determinado pela autoridade religiosa.

47 De acordo com Alexandre de Moraes, para que a regulamentação e a execução desta disposição não sejam inconstitucionais, faz-se necessário que toda e qualquer religião possa ser ensinada nas escolas públicas. $\mathrm{O}$ autor entende que na prática isso é absolutamente impossível (cf. MORAES, 2003: 1984-1985). 
Adicionalmente, a confederação sustenta que a disposição de acordo com a qual o conteúdo do ensino religioso é uma atribuição das diversas autoridades religiosas contraria o art. 33 da Lei Federal n. 9.394/97 que estabelece diferentes padrões para a definição do conteúdo do ensino religioso. Em conformidade com tal lei federal, os sistemas de ensino devem ouvir entidades civis de diversas religiões para definir o conteúdo do ensino religioso. A violação é demonstrada com base no fato de que 0 conceito de autoridade religiosa - que implica uma estrutura administrativa e hierárquica como aquelas presentes nas Igrejas Católicas, Presbiterianas e Judaicas - não é parte da tradição de algumas religiões que tem origem Evangélica ou afro-brasileira.

A ADIN ainda não foi julgada pelo Supremo Tribunal Federal. De qualquer forma, os argumentos apresentados pela Confederação Nacional dos Trabalhadores em Educação - e pelos vários amicus curiae admitidos no processo - parecem ser coerentes com a Constituição Federal e aptos a derrubar a Lei Estadual n. 3.459.

No Estado de São Paulo o ensino religioso previsto no art. 33 da Lei n. 9.394/97 foi regulamentado na Deliberação do Conselho Estadual de Educação - CEE n. 16/2001, com fundamento na Indicação CEE n. 07, aprovada em 25 de julho de 2001, de acordo com a qual o ensino religioso deve ser enfocado na perspectiva constitucional de promoção da cidadania e da dignidade, especialmente na função social da educação em geral, de modo que deve ser enfatizada a reflexão sobre a cidadania e as práticas a ela pertinentes. Assumindo que "não há conhecimento, futuro e vida sem a competência de conviver com as diferenças" a Indicação CEE n. 07/2001 reconhece que "são bem-vindos todos os projetos educacionais (aí se podendo incluir o ensino religioso), que visam, direta ou indiretamente, o trabalho comunitário, a conscientização da responsabilidade pessoal e social e que estimulem e restaurem os valores humanos, de compromisso moral e ético, auxiliando a compreensão do homem e o autoconhecimento". Nesse sentido, de acordo com referida indicação, "o ensino religioso nas escolas deve, antes de tudo, fundamentar-se nos princípios da cidadania e do entendimento do outro" Assim, o CEE recomendou que o ensino religioso fosse tratado como tema transversal, por meio da implementação de uma proposta de abordagem filosófica que permitisse a reflexão sobre valores e princípios éticos e o conhecimento da história das religiões. Também no Estado de São Paulo a implementação do ensino religioso foi arduamente debatida e criticada, especialmente em razão da problemática questão do estabelecimento de religião, vedado pela Constituição de $1988 .{ }^{48}$

48 Vide, entre outros, GIUMBELLI, Emerson. Ensino religioso em escolas públicas no Brasil: notas de pesquisa. Debates do NER (UFRGS), v. 14, p. 50-68, 2009, CURY, Carlos Roberto Jamil. Ensino religioso na escola pública: o retorno de uma polêmica recorrente. Revista Brasileira de Educação, n. 27, p. 183-213, set./dez. 2004; LUI, Janayna de Alencar. Entre crentes e pagãos: ensino religioso em São Paulo. Cadernos de Pesquisa, v. 37, n. 131, p. 333-349, maio/ago. 2007; RANQUETAT JÚNIOR, Cesar. Do confessional ao plural: uma análise sobre o novo modelo de ensino religioso nas escolas brasileiras. Revista Diálogo Educação, Curitiba, v. 8, n. 23, p. 289-305, jan./abr. 2008. 
Neste item a regulamentação da liberdade religiosa no Brasil foi examinada com a finalidade de verificar se o ordenamento jurídico brasileiro adota um princípio de tolerância ou de respeito. As normas relacionadas à garantia da liberdade de consciência e de crença, bem como ao livre exercício de cultos religiosos, à proteção dos locais de adoração, à proibição do estabelecimento de religião, à garantia de assistência religiosa em estabelecimentos de internação coletiva, à acomodação em razão de imperativo de consciência e ao ensino religioso facultativo, todas foram analisadas de modo que fosse possível concluir se o ordenamento jurídico brasileiro adota o princípio da tolerância ou do respeito.

De acordo com tal análise, o ordenamento jurídico brasileiro parece tratar a religião em conformidade com o princípio do respeito. Isso porque pessoas religiosas e não religiosas podem entrar no espaço púbico em iguais condições, sendo que a faculdade de buscar a finalidade última da vida é respeitada pelo Estado. Nesse sentido, o ordenamento jurídico brasileiro garante a liberdade de consciência e de crença, o livre exercício de cultos religiosos e a proteção dos locais de adoração. Adicionalmente, enquanto, de um lado, nenhuma religião pode ser estabelecida pelo Estado, pessoas religiosas podem reivindicar imperativo de consciência, bem como receber assistência religiosa e ensino religioso, se essa for a sua escolha.

Isso demonstra que todos os indivíduos, de acordo com o ordenamento jurídico brasileiro, devem entrar no espaço público em condições iguais e que o Estado é obrigado a fornecer condições para que pessoas religiosas e não religiosas possam buscar a finalidade última da vida, se essa for sua escolha, respeitando em todos os indivíduos a faculdade de realizar tal busca.

\section{Conclusão}

Inicialmente, foi examinada neste artigo a diferença entre o princípio da tolerância e o princípio do respeito no que se refere ao tratamento legal de questões de consciência. Posteriormente, a regulamentação da liberdade religiosa no ordenamento jurídico brasileiro foi analisada com a finalidade de verificar qual desses dois princípios é adotado. Finalmente, conclui-se que o ordenamento jurídico brasileiro adota o princípio do respeito pela faculdade dos indivíduos de buscar pela finalidade última da vida, sendo o Estado obrigado a garantir condições adequadas para as pessoas exercerem tal faculdade, de acordo com suas escolhas autônomas, de modo que todos os indivíduos possam entrar no espaço público em condições iguais.

São Paulo, dezembro de 2010. 


\section{Referências}

BLACKBURN, Simon. Religion and respect. Manuscrito não publicado, fornecido pelo autor durante o Workshop Direito e Filosofia, coordenado por Brian Leiter na University of Chicago Law School, no período compreendido entre setembro de 2008 e maio de 2009.

BIELEFELDT, Heiner. Filosofia dos direitos humanos: fundamentos de um ethos de liberdade universal. São Leopoldo: Unisinos, 2000.

BITTAR, Eduardo Carlos Bianca. O direito na pós-modernidade. Rio de Janeiro: Forense Universitária, 2005.

BOBBIO, Norberto. Tolerância e verdade. In ELOGIO da serenidade e outros escritos morais. Tradução de Marco Aurélio Nogueira. São Paulo: UNESP, 2002. p. 149-155.

LAFER, Celso. O Estado laico. O Estado de S. Paulo, São Paulo, 20 maio 2007. Caderno A2, Espaço Aberto.

COMPARATO, Fábio Konder. A afirmação histórica dos direitos humanos. 2. ed. São Paulo: Saraiva, 2001.

CRETElla JÚNIOR, José. Comentários à Constituição Brasileira de 1988. Rio de Janeiro: Forense Universitária, 1992. v. 1.

D'ADESKY, Jacques. Pluralismo étnico e multiculturalismo: racismos e anti-racismos no Brasil. Rio de Janeiro: Pallas, 2005.

FERREIRA, Pinto. Comentários à Constituição Brasileira. São Paulo: Saraiva, 1989.

FERREIRA FILHO, Manuel Gonçalves. Comentários à Constituição brasileira de 1988. São Paulo: Saraiva, 1990.

GIUMBELLI, Emerson. Ensino religioso em escolas públicas no Brasil: notas de pesquisa. Debates do NER (UFRGS), v. 14, p. 50-68, 2009.

GREEN, Leslie. On being tolerated. University of Oxford Faculty of Law Legal Studies Research Paper Series, Working Paper No. 14/2008.

HABERMAS, Jürgen. Lutas pelo reconhecimento no Estado Democrático Constitucional. In: TAYLOR, Charles (Org.). Multiculturalismo: examinando a política do reconhecimento. Lisboa: Piaget, 1994.

JAMIL CURY, Carlos Roberto. Ensino religioso na escola pública: o retorno de uma polêmica recorrente. Revista Brasileira de Educação, n. 27, p. 183-213, set./dez. 2004.

KYMLICKA, Will. Multicultural citizenship: a liberal theory of minority rights. Oxford: Clarendon Press, 1997. 
LEITER, Brian. Why tolerate religion? Manuscrito não publicado, fornecido pelo autor durante o Workshop Direito e Filosofia, coordenado por Brian Leiter na University of Chicago Law School, no período compreendido entre setembro de 2008 e maio de 2009.

LUI, Janayna de Alencar. Entre crentes e pagãos: ensino religioso em São Paulo. Cadernos de Pesquisa, v. 37, n. 131, p. 333-349, maio/ago, 2007.

NORONHA, Magalhães. Direito Penal. São Paulo: Saraiva, 1968. v. 4.

NUSSBAUM, Martha C. Liberty of Conscience. In: DEFENSE of America's Tradition of Religious Equality. New York: Basic Books, 2008.

MARTINS, Ives Granda; BASTOS, Celso Ribeiro. Comentários à Constituição do Brasil (Promulgada em 5 de outubro de 1988). São Paulo: Saraiva, 1989. v. 2.

Moraes, Alexandre de. Constituição do Brasil Interpretada e Legislação Constitucional. São Paulo: Atlas, 2003.

NEVES, Marcelo. Entre Têmis e Leviatã: uma relação dificil (o Estado Democrático de Direito a partir e além de Luhmann e Habermas). São Paulo: Martins Fontes, 2006.

Justiça e diferença numa sociedade global complexa. Recife: Instituto dos Advogados de Pernambuco. v. 1, n. 1, 2000

PAINE, Thomas. The Founders' Constitution, v. 5, I Emenda (Religião). Doc. 57. Disponível em: $<$ http://press-pubs.uchicago.edu/founders/documents/amendI_religions57.html >.

RANQUETAT JÚNIOR, Cesar. Do confessional ao plural: uma análise sobre o novo modelo de ensino religioso nas escolas brasileiras. Revista Diálogo e Educação, Curitiba, v. 8, n. 23, p. 289305, jan./abr. 2008.

RAZ, Joseph. Autonomy, toleration, and the harm principle. In: GAVISON, Ruth. (Ed.). Contemporary legal philosophy: the influence of H. L. A. Hart". Oxford University Press.

REALE JÚNIOR, Miguel. Tolerância e solidariedade. In: MARCÍLIO, Maria Luiza. A declaração Universal dos Direitos Humanos: sessenta anos: sonhos e realidades. São Paulo : EDUSP, 2008. p. 167-178.

SCHERKERKEWITZ, Iso Chaitz. O direito de religião no Brasil. Revista Nacional de Jurisprudência, ano 3, n. 34, out. 2002.

TASCHNER, Gisela B. A pós-modernidade e a sociologia. Revista USP, São Paulo, n. 42, jun./ago. p. 6-19, 1999.

TOLEDO, Francisco de Assis. Princípios básicos de direito penal. São Paulo: Saraiva, 1986. 